\title{
Identification of Two Products of Mitochondrial Protein Synthesis Associated with Mitochondrial Adenosine Triphosphatase from Neurospora crassa
}

\author{
Gerhard JACKL and Walter SEBALD \\ Institut für Physiologische Chemie und Physikalische Biochemie der Universität München \\ (Received December 23, 1974)
}

Soluble mitochondrial ATPase $\left(\mathrm{F}_{1}\right)$ isolated from Neurospora crassa is resolved by dodecylsulfate-gel electrophoresis into five polypeptide bands with apparent molecular weights of 59000 , $55000,36000,15000$ and 12000 .

At least nine further polypeptides remain associated with ATPase after disintegration of mitochondria with Triton X-100 as shown by the analysis of an immunoprecipitate obtained with antiserum to $F_{1}$ ATPase.

Two of the associated polypeptides with apparent molecular weights of 19000 and 11000 are translated on mitochondrial ribosomes, as demonstrated by incorporation in vivo of radioactive leucine in the presence of specific inhibitors of mitochondrial (chloramphenicol) and extramitochondrial (cycloheximide) protein synthesis.

The appearance of mitochondrial translation products in the immunoprecipitated ATPase complex is inhibited by cycloheximide. The same applies for some of the extramitochondrial translation products in the presence of chloramphenicol. This suggests that both types of polypeptides are necessary for the assembly of the ATPase complex.

Up to now four products of mitochondrial protein synthesis have been detected in functional membrane proteins isolated from mitochondria of Neurospora crassa. Three polypeptides present in cytochrome oxidase $[1-3]$ and one present in cytochrome $b[4]$ are made on mitochondrial ribosomes. Mitochondrial ATPase was investigated in order to identify further products of mitochondrial protein synthesis in this organism.

With yeast it has already been shown that mitochondrial and extramitochondrial protein synthesis cooperate in the formation of an oligomycin-sensitive ATPase. The mitochondrial contribution is confined to a highly insoluble lipoprotein fraction [5], whereas the other constituents of the enzyme, namely $F_{1}$ ATPase $[6,7]$ and oligomycin-sensitivity-conferring protein [8], are synthesized outside the organelle. Four mitochondrial translation products have been identified in the isolated enzyme by incorporation

Enzyme. ATP phosphohydrolase or ATPase (EC 3.6.1.3). in vivo of radioactive amino acids in the presence of cycloheximide [9].

The present results obtained with Neurospora crassa confirm the existence of mitochondrial translation products associated with ATPase. However, only two polypeptides synthesized on mitochondrial ribosomes could be detected in an ATPase complex isolated from this organism by immunoprecipitation with antiserum to $F_{1}$ ATPase. This method of isolation was originally devised by Tzagoloff and Meagher [10].

\section{METHODS}

\section{Cultivation and Labelling of Cells}

Neurospora crassa wild type $74 \mathrm{~A}$ was grown in Vogel's minimal medium under aeration [1]. Mitochondrial proteins were labelled with $\left[{ }^{14} \mathrm{C}\right]$ leucine or $\left[{ }^{3} \mathrm{H}\right]$ leucine by growing cells of a $15-\mathrm{h}$ culture for $3 \mathrm{~h}$ in the presence of the radioactive amino acid. Special growth conditions in the presence of inhibitors are detailed in the legends to the figures. 
Preparation of Mitochondria,

Soluble Mitochondrial ATPase $\left(F_{1}\right)$ and Antisera

Mitochondria were prepared after disintegration of the cells with a grind mill [1]. Soluble mitochondrial ATPase $\left(F_{1}\right)$ could be isolated according to the procedures developed either for the beef heart [11] or for the yeast $[12,13]$ enzyme. ATPase activity was determined using ATP as substrate [13].

Antisera against $F_{1}$ ATPase were obtained from rabbits by standard procedures (see [14]).

\section{Immunoprecipitation}

All operations were performed at $0-4{ }^{\circ} \mathrm{C}$. Mitochondrial suspensions $(20-30 \mathrm{mg} / \mathrm{ml})$ were diluted with buffer $(1 \%$ Triton X-100, $0.3 \mathrm{M} \mathrm{KCl}, 10 \mathrm{mM}$ Tris-acetate $\mathrm{pH} 7.5$ ) to a final concentration of $2 \mathrm{mg} /$ $\mathrm{ml}$ and centrifuged immediatcly in an Eppendorf microcentrifuge for $5 \mathrm{~min}$ at $12000 \times$ g. $95-100 \%$ of the mitochondrial protein was found in the supernatant. The supernatant was incubated with an amount of antiserum sufficient to reach maximal precipitation. The reaction was complete after $2 \mathrm{~h}$ and the precipitate was isolated by centrifugation for $2 \mathrm{~min}$ in the microcentrifuge. The pellets were washed twicc in buffer containing $1 \%$ Triton X-100, $0.3 \mathrm{M}$ $\mathrm{KCl}, 10 \mathrm{mM}$ Tris - acetate $\mathrm{pH} 7.5$ and once in $10 \mathrm{mM}$ Tris $\rightarrow$ acetate $\mathrm{pH} 7.5$.

\section{Dodecylsulfate-Gel Electrophoresis}

The washed immunoprecipitates were suspended in $10-20 \mu \mathrm{l}$ of $10 \mathrm{mM}$ Tris - acetate buffer $\mathrm{pH} 7.5$, dissolved by addition of dodecylsulfate buffer (final concentrations: $2 \%$ dodecylsulfate, $5 \%$ mercaptoethanol, $0.1 \mathrm{M}$ Tris-acetate $\mathrm{pH} 8.5$ ) and incubated over night at $0-4^{\circ} \mathrm{C}$. Immunoprecipitates obtained with some antisera could not be completely dissociated by this procedurc, and it was necessary to preincubate in $0.2 \mathrm{M} \mathrm{NaOH}$ for $10 \mathrm{~min}$ at room temperature before addition of dodecylsulfate buffer [9]. $20 \mu$ l of solution containing $20-50 \mu \mathrm{g}$ of mitochondrial protein were separated on $12.5 \%$ gels [3]. Described methods have been used for measurement of radioactivity in gel slices and for calibration of the molecular weights [3]. Protein was estimated by the procedure of Lowry et al. [15].

\section{RESULTS}

\section{Subunit Composition}

of Soluble Mitochondrial ATPase $\left(F_{1}\right)$

$F_{1}$ ATPase from Neurospora crassa is separated by dodecylsulfate-gel electrophoresis into five poly-

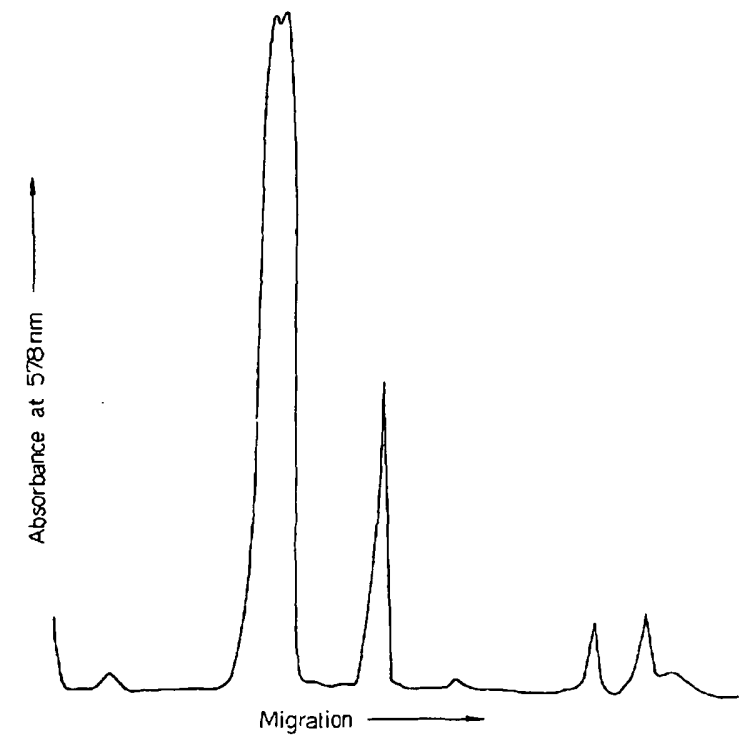

Fig. 1. Subunit composition of soluble mitochondrial ATPase $\left(F_{1}\right)$. The densitometric trace was recorded after separation of the enzyme by dodecylsulfate-gel electrophoresis and staining with Coomassie brilliant blue

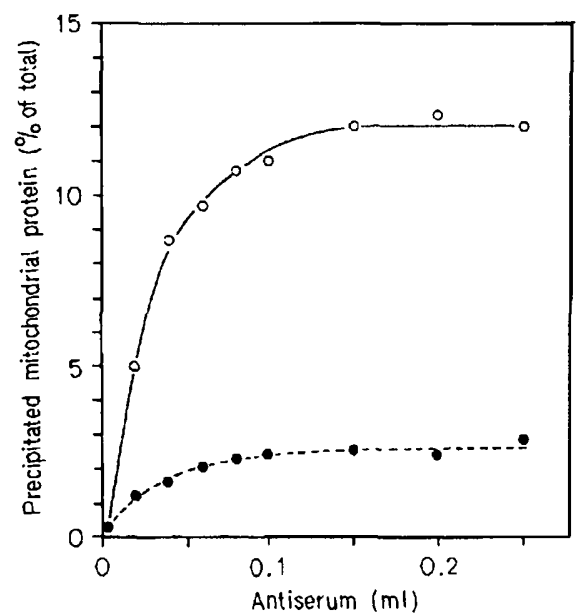

Fig. 2. Titration of Triton $X-100$ solubilized mitochondrial proteins with antiserum to $F_{1}$ ATPase. Mitochondrial protcins wcre lahelled as described in the legend to Table 2 (column B). 0.25-1nl samples of the solubilized proteins were incubatcd with equal volumes of rabbit serum. The amounts of antiserum to $F_{2}$ ATPase indicated on the abscissa were brought to $0.25 \mathrm{ml}$ by the addition of control serum. The ordinate documents the precipitated labelled protein as a percentage of total milochondrial protein. $(\mathrm{O}-\mathrm{O}-\mathrm{O}){ }^{14} \mathrm{C}$ control label; (- . $)^{3} \mathrm{H}$ cycloheximide-resistant label

peptide bands with apparent molecular weights of $59000,56000,36000,15000$ and 12000 (Fig. 1). The isolated enzyme is rapidly inactivated at $0{ }^{\circ} \mathrm{C}$ and it is not inhibited by oligomycin. Enzymic activities between 60 and 100 units/mg protein were measured with different preparations. Similar subunit compositions and properties have been reported for $F_{1}$ 


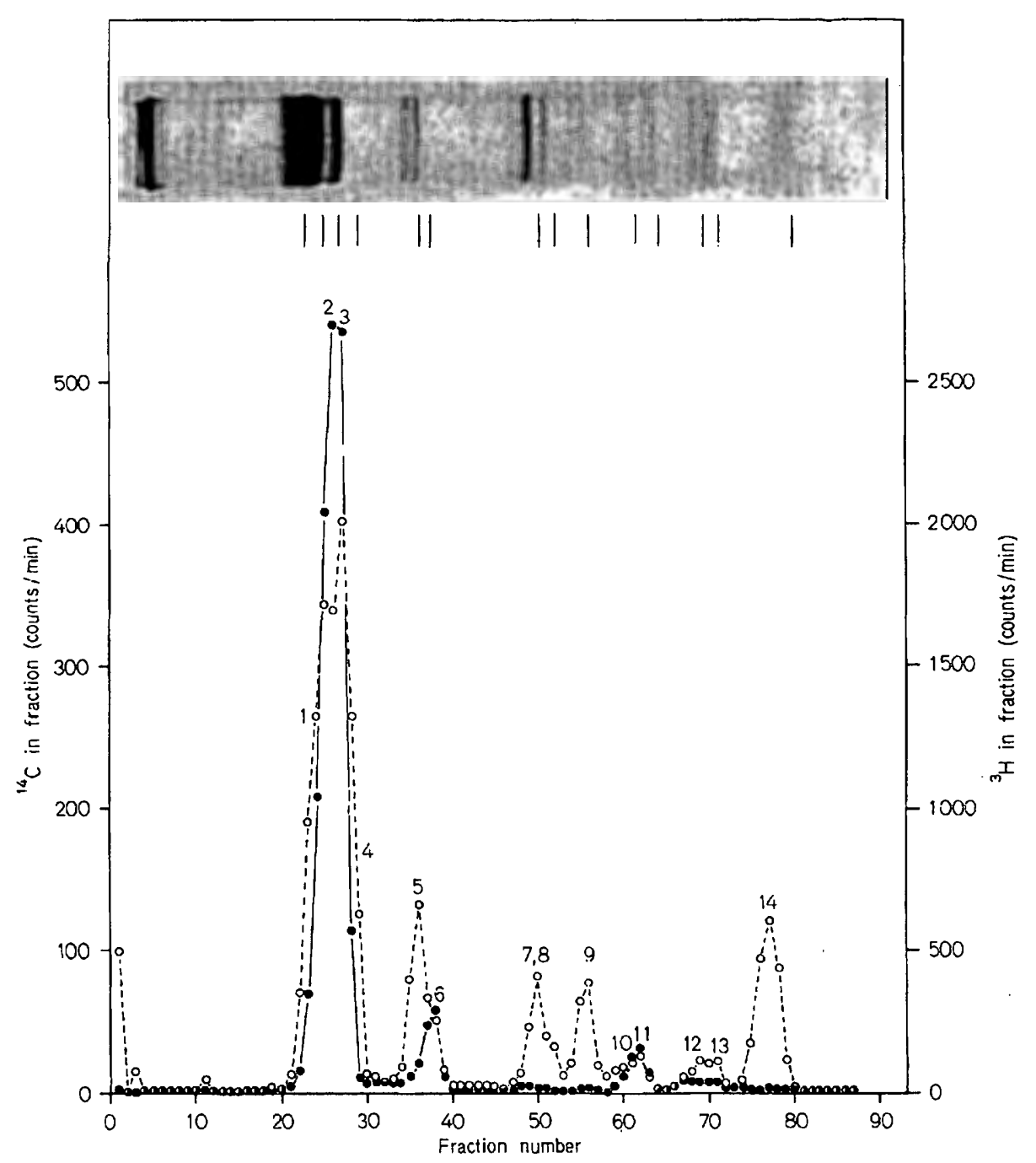

Fig. 3. Coelectrophoresis of $F_{1}$ ATPase (-—) and of mitochondrial proteins precipitated with antiserum to $F_{1}$ ATPase $(0 \ldots-0)$. The immunoprecipitatc was obtained from cells labelled with $\left[{ }^{14} \mathrm{C}\right.$ lleucine (see Methods). $\mathrm{F}_{1}$ ATPase was isolated from cells labelled with $\left[{ }^{3} \mathrm{H}\right]$ leucinc. Both proteins were dissolved in dodecyl-

sulfate buffer, mixcd and then submitted to gel clectrophoresis. The upper part of the figure shows a gel-electrophoretic separation of immunoprecipitated ATPase after staining with Coomassie brilliant blue. In this particular experiment no mercaptoethanol was prescnt during the solubilization of the proteins

ATPase isolated from beef heart $[11,16,17]$, rat liver $[18,19]$ and Schizosaccharomyces pombe $[20]$.

\section{Immunoprecipitate Obtained with Antiserum to $F_{1}$ ATPase from Mitochondria Solubilized with Triton $X-10$}

Antiserum to $F_{1}$ ATPase at optimal concentrations precipitates $13 \%$ to $15 \%$ of whole mitochondrial protein (Fig. 2). The precipitation is caused by specific antibodies, since control serum gives only minimal reaction.

To compare the polypeptide composition of the immunoprecipitate with that of the $F_{1}$ ATPase both proteins were mixed and submitted to dodecylsulfate- gel clectrophoresis (Fig. 3). The immunoprecipitate had been obtained from cells labelled with $\left[{ }^{14} \mathrm{C}\right]-$ leucine, and the $F_{1}$ ATPase had been isolated from cells labelled with $\left[{ }^{3} \mathrm{H}\right]$ leucine. As demonstrated in Fig. 3, not only the five subunits of $F_{1}$ ATPase are precipitated but also numerous additional polypeptides. The distribution of the ${ }^{14} \mathrm{C}$ label shows seven main peaks containing the amounts of radioactivity compiled in Table 1. Shoulders which are more or less pronounced in different separations (e.g. Fig. 4-7) indicate that some of these peaks contain more than one polypeptide. A better resolution is observed after staining the gels with Coomassie blue (Fig. 3). Those stained bands which can be correlated with the labelling pattern have been numbered from 1 to 14 . (The 


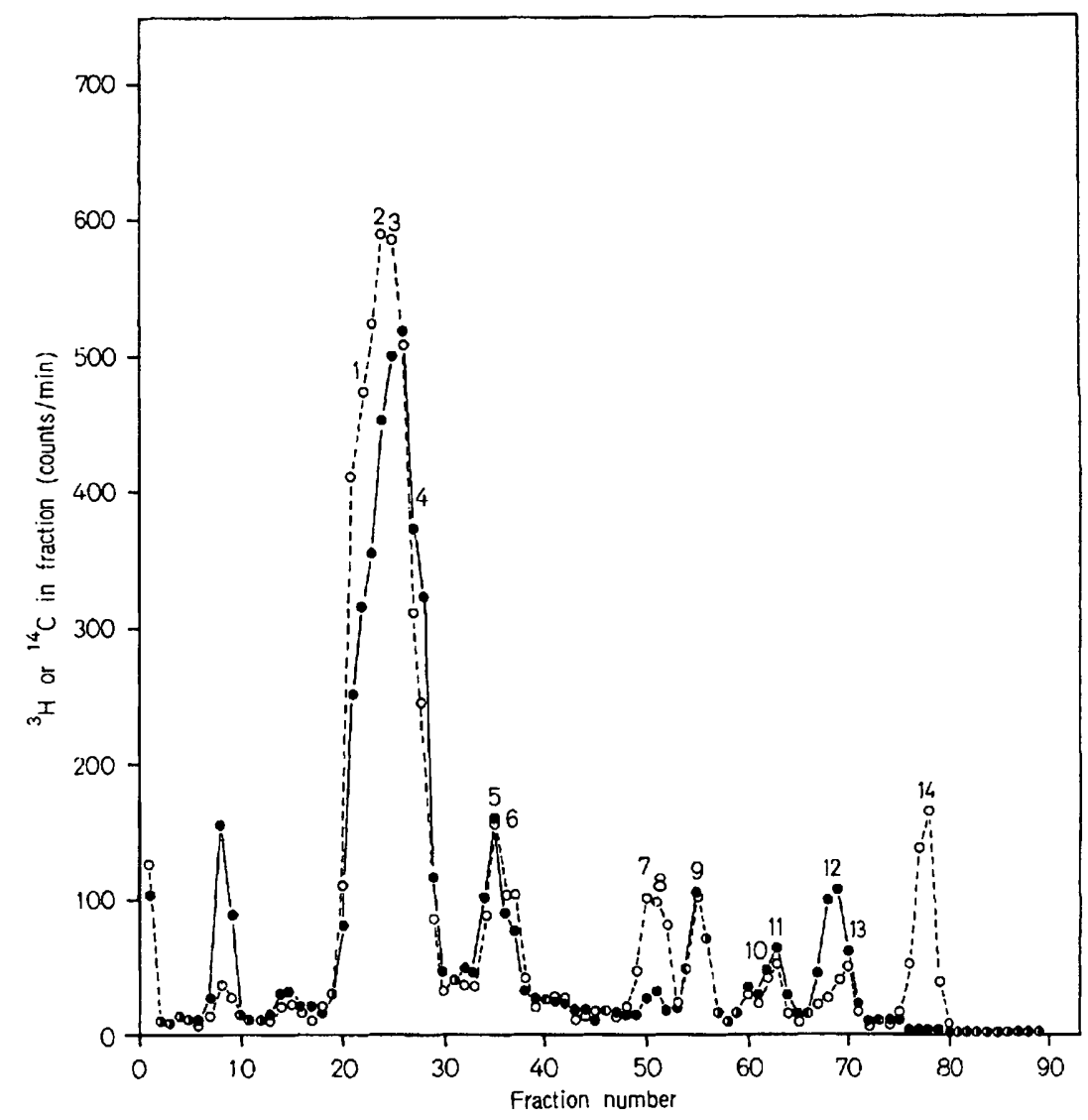

Fig.4. Distribution of homogeneous $\left[{ }^{14} \mathrm{C}\right.$ leucine (O-- $\mathrm{O}$ ) and ${ }^{3}$ H Jhistidine (-) over the electrophoretic fractions of immunoprecipitated ATPase. Cells were labelled by a simultaneous

Table 1. Amounts of homogeneous $\left({ }^{14} \mathrm{C}\right.$ lleucine present in electrophoretic fractions of immunoprecipitated ATPase

The percenlage contents were evaluated from electrophorctic separations of immunoprecipitated ATPase as shown in Fig. 3-7. The values represent the average of 12 separations. The proteins were labelled with $\left[{ }^{14} \mathrm{C}\right]$ leucine as described under Methods

\begin{tabular}{ll}
\hline Components of ATPase & Homogeneous $\left[{ }^{14} \mathrm{C}\right]$ leucine \\
\hline & $\%$ of total \\
$1,2,3,4$ & $52.4 \pm 5.1$ \\
5,6 & $10 \pm 1.5$ \\
7,8 & $9 \pm 1.1$ \\
9 & $6.7 \pm 0.8$ \\
10,11 & $3.8 \pm 0.8$ \\
12,13 & $4.8 \pm 1$ \\
14 & $13.1 \pm 2.6$ \\
\hline
\end{tabular}

heavy band near the origin can be attributed to the rabbit gammaglobulins. They exhibit a high molecular weight, since disulfide bridges have not been reduced with mercaptoethanol in this particular experiment.) The subunits of $F_{1}$ ATPase exhibit the same electrophoretic mobility as components $2,3,6$, incorporation of $\left[{ }^{14} \mathrm{C}\right]$ leucine and $\left[{ }^{3} \mathrm{H}\right]$ histidine for $3 \mathrm{~h}$. The isolated immunoprecipitate was separated by dodecylsulfate-gel electrophoresis

11 and 12 . The additional polypeptides show apparent molecular weights of $65000(1), 48000(4), 38000(5)$, $22000(7), 21000(8), 19000(9), 16000(10), 11000(13)$ and less than 8000 (14).

In order to confirm the polypeptide composition described above, an immunoprecipitate labelled simultaneously with $\left[{ }^{3} \mathrm{H}\right]$ histidine and $\left[{ }^{14} \mathrm{C}\right]$ leucine was separated by gel electrophoresis (Fig. 4). Components $1,2,3$ and 4 can be distinguished by their individual

Fig. 5. Cycloheximide-resistant label in immunoprecipitated ATPase after different labelling procedures. (A) Cclls were labelled according to the protocol detailed in Table 2 (column A). A ${ }^{3} \mathrm{H}^{14} \mathrm{C}^{1}$ ratio of 2.4 and a specific ${ }^{14} \mathrm{C}$ radio-activity of 180000 counts $\times \mathrm{min}^{-1} \times \mathrm{mg}^{-1}$ was determined in the whole mitochondrial protein in this particular experiment. The isolated immunoprecipitate was separated by dodecylsulfate-gel electrophoresis. $(\mathrm{O} \cdots--\mathrm{O}){ }^{14} \mathrm{C}$ control label; ${ }^{3} \mathrm{H}$ radioactivity incorporated during $60 \mathrm{~min}$ in the presence of cycloheximide. (B,C) The immunoprecipitates described in Table 2 (columns $B$ and $C$ ) werc separated by dodecylsulfate-gel electrophoresis. (O-- $\mathrm{O}){ }^{14} \mathrm{C}$ control label: $\left(\mathrm{O}_{-}-{ }^{3} \mathrm{H}\right.$ radioactivity incorporated after a transitory incubation with chloramphenicol in the presence of cycloheximide during (B) 60 min and (C) 2 min plus $60-$ min chase 


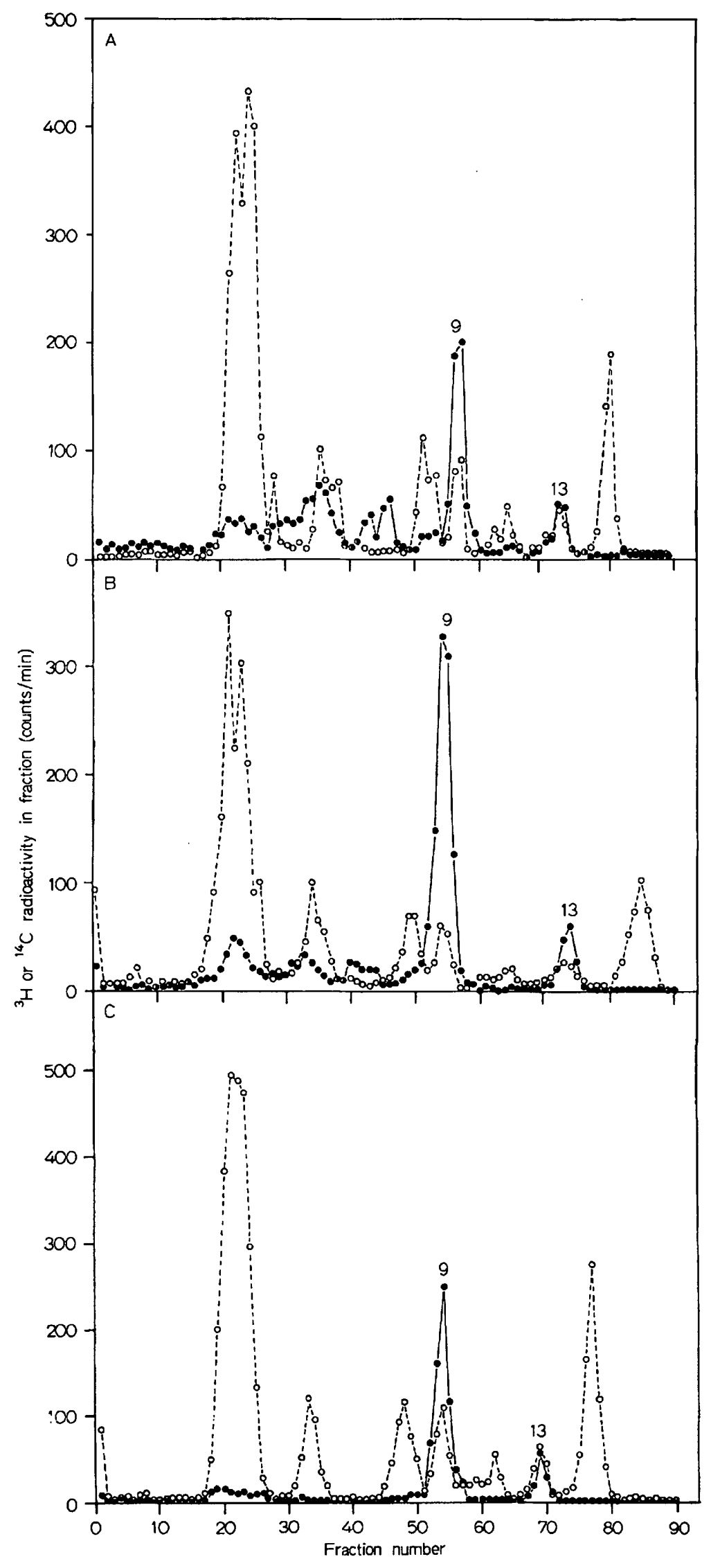

Eur. J. Biochem. 54 (1975) 
Table 2. Enrichment of cycloheximide-resistant label in component 9 of immunoprecipitated ATPase after different labelling procedures Column $\mathrm{A}$ and $\mathrm{B}$ : Cclls grown for $15 \mathrm{~h}$ in a $2-1$ culture were labelled for $3 \mathrm{~h}$ with $\left[{ }^{14} \mathrm{C}\right]$ leucine $(0.125 \mathrm{mCi} / \mathrm{l})$. Thereafter the culturc was divided into equal parts. One half was incubated with $4 \mathrm{mg}$ chloramphenicol per $\mathrm{ml}$ for $30 \mathrm{~min}$. Then both cultures were washed separately threc times with fresh culture medium, and aerated in 11 medium for another $15 \mathrm{~min}$. To both cultures $0.1 \mathrm{mg}$ cycloheximide per $\mathrm{ml}$ was adled, and $2 \mathrm{~min}$ later $\left[{ }^{3} \mathrm{HI}\right]$ leucine $(2.5 \mathrm{mCi} / \mathrm{l})$. After $60 \mathrm{~min}$ the cells were harvested. The specific ${ }^{14} \mathrm{C}$ radioactivity of whole mitochondrial proteins was 140000 counts $\times \mathrm{min}^{-1} \times \mathrm{mg}^{-1}$ in both preparations. Column $\mathrm{C}$ : Cells were labelled with $\left[{ }^{14} \mathrm{C}\right]-$ leucine and preincubated with chloramphenicol as described above. 2 min after cycloheximide $\left[{ }^{3} \mathrm{H}\right]$ leucine $(10 \mathrm{mCi} / \mathrm{l})$ was added, and 2 min later unlabelled leucinc to a final concentration of $5 \mathrm{mM}$. After $60 \mathrm{~min}$ the cells were harvested. The specific ${ }^{14} \mathrm{C}$ radioactivity of wholc mitochondrial protein was 150000 counts $\times \mathrm{min}^{-1} \times \mathrm{mg}^{-1}$

\begin{tabular}{ll}
\hline Protcin fractions & $\begin{array}{l}\text { Specific radioactivity }\left({ }^{3} \mathrm{H} ;{ }^{14} \mathrm{C} \text { ratios }\right) \\
\text { after labelling in the presencc } \\
\text { of cycloheximide for }\end{array}$ \\
\hline $60 \mathrm{~min} \quad 60 \mathrm{~min}$ & $\begin{array}{l}2 \text { min plus } \\
60 \text {-min } \\
\text { chasc }\end{array}$
\end{tabular}

after a transitory incubation with

chloramphenicol

(A)

(B)

(C)

\begin{tabular}{llll}
\hline $\begin{array}{l}\text { Whole mitochondrial } \\
\text { protein }\end{array}$ & $1.64(=1)$ & $2.32(=1)$ & $0.53(=1)$ \\
$\begin{array}{l}\text { Immunoprecipitated } \\
\text { ATPase }\end{array}$ & $0.2(0.12)$ & $0.47(0.2)$ & $0.1(0.2)$ \\
Component 9 & $1.1(0.7)$ & $5.5(2.4)$ & $2.0(3.8)$ \\
\hline
\end{tabular}

${ }^{3} \mathrm{H} /{ }^{14} \mathrm{C}$ ratios, as can components 5 and 6 and components 12 and 13. Component 9 exhibits constant ${ }^{3} \mathrm{H} /{ }^{14} \mathrm{C}$ ratios over all peak fractions and may therefore represent a single polypeptide. Remarkably, no histidine is present in component 14 , and only low levels of this amino acid can be detected in components 7 and 8.

It is concluded from these results that the immunoprecipitated ATPase complex contains at least 14 polypeptides: the five subunits of $F_{1}$ ATPase and nine additional polypeptides. The whole polypeptide pattern resembles that of oligomycin-sensitive ATPase purified from mitochondrial membranes of yeast [10] or becf hearl $[21,22]$.

\section{Mitochondrial Sy:nthesis of Polypeptides Associated with ATPase}

A selective labelling of mitochondrial or extramitochondrial translation products can be achieved by incorporation in vivo of radioactive amino acids in the presence of specific inhibitors of extramito-
Table 3. Labelling of immunoprecipitated ATPase in the presence of chloramphenicol

Cells grown for $15 \mathrm{~h}$ in a $2-1$ culture were labclled for $3 \mathrm{~h}$ with $\left[{ }^{14} \mathrm{C}\right]$ leucine $\left(0.125 \mathrm{mCi}^{\prime} / \mathrm{l}\right)$. Thereafter $4 \mathrm{mg}$ chloramphenicol per $\mathrm{ml}$ was added, and $5 \mathrm{~min}$ later $\left[{ }^{3} \mathrm{H}\right]$ leucine $(1 \mathrm{mCi} /)$. After $30 \mathrm{~min}$ one half of the cells was harvested. The remaining cells were washed three times with fresh culture medium to remove the chloramphenicol and grown for another hour. Whole mitochondrial protcins isolated from both cells exhibited specific ${ }^{14} \mathrm{C}$ radioactivities of 145000 counts $\times \min ^{-1} \times \mathrm{mg}^{-1}$. The immunoprecipitates were separated on dodecylsulfate gels as shown in Fig. 7 A and B

\begin{tabular}{lll}
\hline Protein fractions & $\begin{array}{l}\text { Specific radioactivity } \\
\left(\mathrm{H}^{14} \mathrm{C} \text { ratios }\right)\end{array}$ \\
\cline { 2 - 3 } & $\begin{array}{l}\text { before washing after washing } \\
\text { out of } \\
\text { chloram- } \\
\text { phenicol } \\
\text { (A) }\end{array}$ & $\begin{array}{l}\text { out of } \\
\text { chloratm- } \\
\text { phenicol } \\
(B)\end{array}$ \\
\hline Whole mitochondrial protein & $2.0(=1)$ & $2.0(=1)$ \\
Immunoprecipitated ATPasc & $1.64(0.85)$ & $1.9(0.95)$ \\
Component 9 & $0.33(0.15)$ & $0.2(0.1)$ \\
\hline
\end{tabular}

chondrial (cycloheximide) or mitochondrial (chloramphenicol) protein synthesis. In previous studies with cytochrome oxidase [2,3], however, it has been shown that in the presence of either inhibitor mainly precursor polypeptides are labelled, which can be assembled into the functional enzyme only by special techniques. In the present studies concerning the site of synthesis of the polypeptides associated with ATPase the same problems were encountered and could be overcome by the same techniques.

Cycloheximide strongly inhibits amino acid incorporation into all polypcptides precipitated with antiserum to $F_{1}$ ATPase (Fig. 5A). Some label appears in component 9 and 13 , but the amounts vary from experiment to experiment and no enrichment is observed if compared to the label of wholc mitochondrial protein (Table 2A). Cycloheximide-resistant label present in further electrophoretic fractions cannot be correlated with any control label.

As reported earlier [3] and as demonstrated in Table 2B, cycloheximide-resistant amino acid incorporation is stimulated after a transitory incubation of the cells with chloramphenicol. After this treatment label is found to be enhanced in the wholc mitochondrial protein (Table $2 \mathrm{~B}, \mathrm{C}$ ) and to a still larger extent in components 9 and 13 of the ATPase complex (Fig. 5B, C). The specific radioactivity of component 9 is enriched 2.4-fold compared to whole mitochondrial protein after a labelling period of $60 \mathrm{~min}$, and 3.8-fold after a pulse chase labelling. Radioactivity appearing at higher molecular weights is still present after a 60-min incorporation, but has nearly disappeared in the pulse chase experiment. 


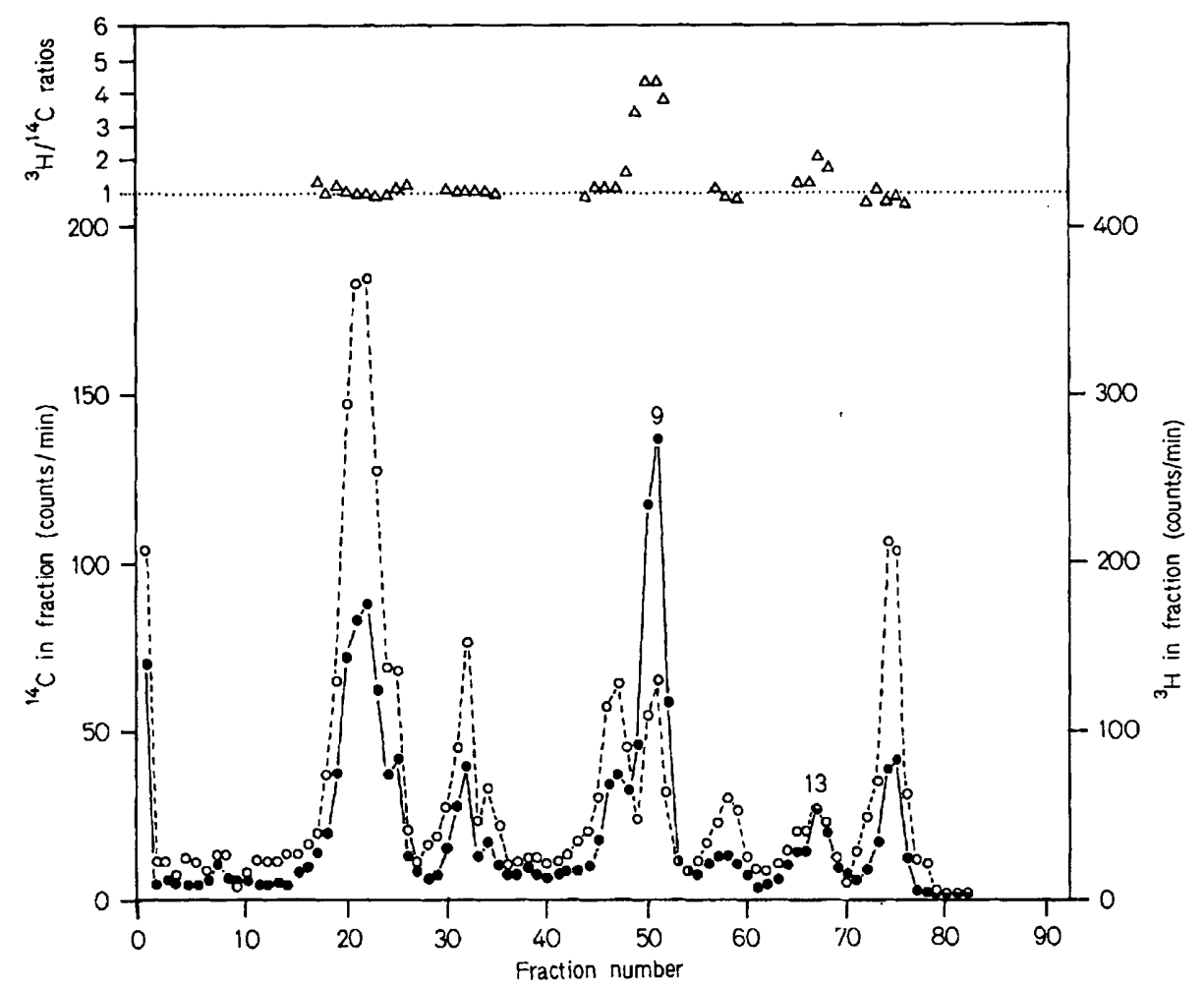

Fig. 6. Cycloheximide-resistant labelling of immunoprecipitated ATPase after washing out the inhibitor and further growth of the cells. A 15 -h culture of cclls was labelled for $3 \mathrm{~h}$ with $\left[{ }^{14} \mathrm{C}\right]$ lcucine $(0.08 \mathrm{mCi} /$ 1). After a transitory incubation for $30 \mathrm{~min}$ with chloramphenicol $(4 \mathrm{mg} / \mathrm{ml})$, cycloheximide $(0.1 \mathrm{mg} / \mathrm{ml})$ was added and 2 min later $\left[{ }^{3} \mathrm{H}\right]$ leucine $(1.2 \mathrm{mCi} / \mathrm{l})$. After a labelling period of $60 \mathrm{~min}$, cells were washed three times with fresh culture medium and grown

These results indicate the presence of mitochondrial translation products in components 9 and 13 of the ATPase complex. In order to examine wether or not further polypeptides are synthesized under the action of cycloheximide but not integrated into the ATPase complex, the following wash-out experiment was performed (Fig.6). Cycloheximide was removed from the cells after the labelling period, and the cells were grown in fresh culture medium for another $4 \mathrm{~h}$. Extramitochondrial protein synthesis is thus reactivated and the assembly of the ATPase complex proceeds. It must be considered, however, that only a small percentage of the added radioactive leucine is utilized in the presence of cycloheximide. Most of the tracer remains in the cellular leucine pool and cannot be washed out or chased [2]. After washing out the inhibitor, the residual radioactive leucine appears in all cellular proteins. This unspecific labelling can be calculated, since it is distributed in the same relation over the components of the ATPase complex as the control label. Additional radioactivity, which must have been incorporated in the presence of cycloheximide, is observed only in the case of components 9 and 13. As in the pulse chase experi-

for another $4 \mathrm{~h}$. The specific ${ }^{14} \mathrm{C}$ and ${ }^{3} \mathrm{H}$ radioactivity of whole mitochondrial protein was 120000 and 240000 counts $\times \min ^{-1}$ $\times \mathrm{mg}^{-1}$ respectively. The isolated immunoprecipitate was separated by dodccylsulfatc-gel clectrophoresis. $(0---0){ }^{14} \mathrm{C}$ control label; $(-)^{3} \mathrm{H}$ radioactivity incorporated during and after the incubation with cycloheximide

ment no other mitochondrial translation products can be detected in the ATPase complex.

This suggests that all components except 9 and 13 are translated on extramitochondrial ribosomes. The extramitochondrial origin of these polypeptides can be further demonstrated by labelling experiments after inhibition of mitochondrial protein synthesis. After incorporation of $\left[{ }^{3} \mathrm{H}\right]$ leucine for $30 \mathrm{~min}$ in the presence of chloramphenicol, labelling of the ATPase complex is $15 \%$ lower than that of whole mitochondrial protein (Table 3A). Label is found to be strongly reduced in component 9 , and also but to a lower extent in components 7, 8, 10, 13 and 14 (Fig. 7 A). In order to see if the labelling of these components is prevented due to an incomplete assembly with the ATPase complex or due to an inhibition of synthesis, the chloramphenicol was removed after the labelling period and the cells were grown for another hour in fresh medium. The labelling of the whole mitochondrial protein is not changed by this procedure (Table 3B). The label enhances, however, in components $7,8,10$ and 14 of the ATPase complex (Fig. 7B). In components 9 and 13 a $90 \%$ and $50 \%$ inhibition of labelling persists. It may be mentioned 


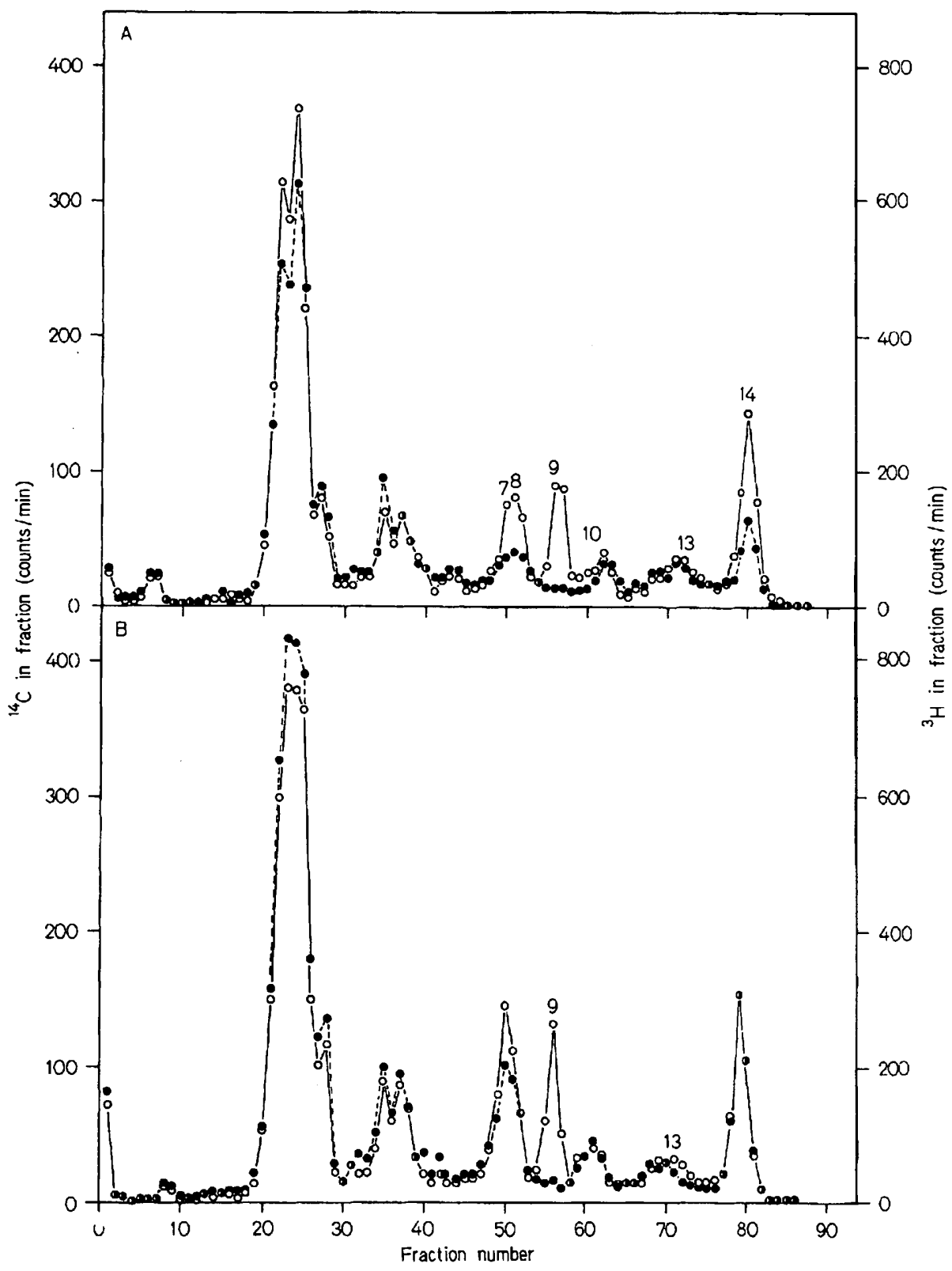

Fig. 7. Chloramphenicol-resistant labelling pattern of immunoprecipitated ATPase before and after washing out the inhibitor. The immunoprecipitates described in Table 3 were separated by dodecylsulfate-gel electrophoresis. (O-...- - $)^{14} \mathrm{C}$ control label;

${ }^{3} \mathrm{H}$ radioactivity incorporated (A) during a 30 -min labelling period in the presence of chloramphenicol or (B) after removal of chloramphenicol and further growth of the cells

that in the absence of chloramphenicol all components reach the same specific radioactivity $30 \mathrm{~min}$ after addition of the $\left[{ }^{3} \mathrm{H}\right]$ leucine.

\section{Comparison of Component 9 of the ATPase Complex} with the Mitochondrially Synthesized Subunits of Cytochrome Oxidase

In previous studies a mitochondrial site of synthesis was demonstrated for subunits I, II and III of cytochrome oxidase purified from Neurospora crassa [3]. These polypeptides were compared by coelectrophoresis with the mitochondrial translation products associated with ATPase (Fig. 8). The ATPase complex had been labelled with $\left[{ }^{3} \mathrm{H}\right]$ leucine in the presence of cycloheximide, and cytochrome oxidase had been labelled with $\left[{ }^{14} \mathrm{C}\right]$ leucine in the absence of inhibitor. Both proteins were isolated by means of specific antisera, mixed and then submitted to dodecylsulfategel electrophoresis. Component 9 of the ATPase 


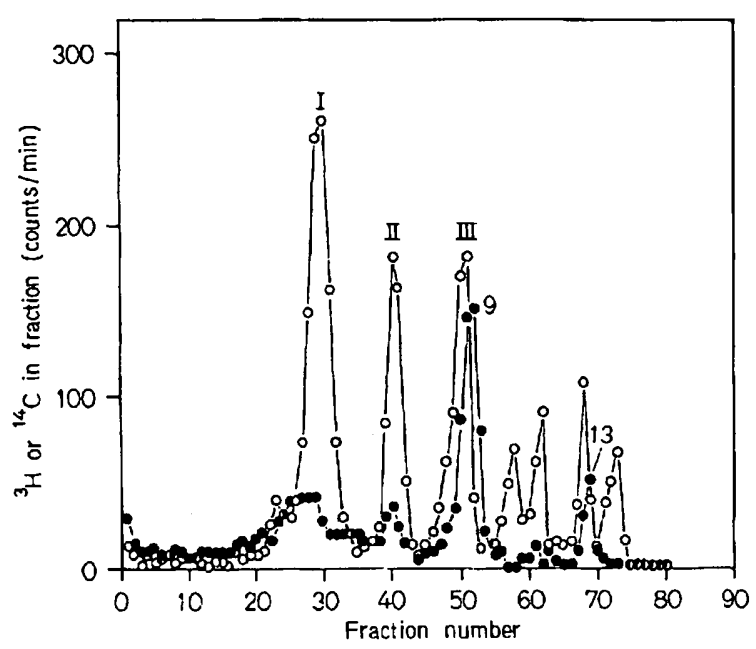

Fig. 8. Coelectrophoresis of cytochrome oxidase and of mitochondrial translation products associated with ATPase. Cytochrome oxidase labelled homogeneously with $\left[{ }^{14} \mathrm{C}\right]$ leucine was isolated by immunoprecipitation with antiserum to cytochrome oxidase [14] as described under Methods. Immunoprecipitated ATPase was isolated from cells labelled with $\left[{ }^{3} \mathrm{H}\right]$ leucine in the presence of cycloheximide as detailed in Table 2 (column B). Both proteins were dissolved in dodecylsulfate buffer, mixed and then submitted to dodecylsulfategel clectrophoresis. $\left(\mathrm{O}-\mathrm{O}-\mathrm{O}{ }^{14} \mathrm{C}\right.$ radioactivity representing subunits of cytochrome oxidase; $(-)^{3} \mathrm{H}$ radioactivity representing mitochondrial translation products associated with ATPase

complex can be distinguished from subunit III of cytochrome oxidase by a slightly higher electrophoretic mobility. This result is in accordance with earlier studies [3], where the existence of two mitochondrial translation products with a molecular weight of about 20000 was postulated.

\section{DISCUSSION}

The ATPase complex described in the present communication is isolated by immunoprecipitation with antiserum to $F_{1}$ ATPase. It is uncertain if the immunoprecipitate represents whole oligomycin-sensitive ATPase, since it has not yet been possible to isolate the functional enzyme from Neurospora crassa in a reasonably pure state. Nevertheless, this ATPase complex contains, besides the five subunits of $F_{1}$ ATPase, a specific pattern of at least nine additional polypeptides. These additional polypeptides apparently are tightly associated with the $F_{1}$ ATPase, since they are not split off by the fairly high concentrations of Triton X-100 (1\%) and $\mathrm{KCl}(0.3 \mathrm{M})$ used for the solubilization of the membranes and the isolation of the immunoprecipitate.

Two polypeptides associated with $F_{1}$ ATPase are synthesized on mitochondrial ribosomes. In double labelling experiments the one polypeptide with a molecular weight of 19000 can be clearly correlated with component 9 of the ATPase complex. In this component, control and cycloheximide-resistant label can be superimposed and labelling is inhibited by $90 \%$ in the presence of chloramphenicol. The other mitochondrial translation product with a molecular weight of 11000 may be correlated with component 13 of the ATPase complex. The incomplete separation of this component in the gel electrophoresis may explain the lower enrichment of cycloheximideresistant label and the lower inhibition of labelling by chloramphenicol if compared to component 9 . Nevertheless, a constant percentage of cycloheximideresistant label occurs in component 13 under different labelling conditions and a $50 \%$ inhibition of labelling is observed in the presence of chloramphenicol. This indicates that this mitochondrial translation product is also a constituent of the ATPase complex and that it is present in substantial amounts.

Component 9 only binds the Coomassie blue stain poorly, and its apparent molecular weight is found to be higher if the dodecylsulfate-gel electrophoresis is performed at higher gel concentrations. Both properties have also been observed in mitochondrial translation products present in cytochrome oxidase from yeast $[23,24]$ and Neurospora crassa [3].

In yeast, four polypeptides synthesized in the presence of cycloheximide could be identified in an oligomycin-sensitive ATPase isolated after reconstitution of the enzyme in vitro. The same four polypeptides were detected when the enzyme was isolated by immunoprecipitation with antiserum to whole oligomycin-sensitive ATPase $[9,25,26]$. Molecular weights of $29000,22000,12000$ and 7500 were determined for these mitochondrial translation products. The bulk of the cycloheximide-resistant label was found in the polypeptide with a molecular weight of 7500 . This low-molecular-weight product could be isolated by extraction with chloroform-methanol and thinlayer chromatography $[9,25,28]$. It contains an unusually high percentage of hydrophobic amino acids. The same polypeptide could be isolated starting from whole mitochondrial membranes $[27,28]$.

No mitochondrial translation product with a molecular weight of 7500 can be detected after gel-electrophoretic separation of the ATPase complex from Neurospora crassa as described in this paper. Extraction of the ATPase complex with chloroform methanol, treatment with acid $(0.2 \mathrm{M})$ or base $(0.2 \mathrm{M})$ and heating in dodecylsulfate buffer does not result in the appearance of low-molecular-weight material. From whole mitochondrial membranes of Neurospora crassa, however, a polypeptide with a molecular weight of approximately 8000 can be isolated by chloroform-methanol extraction and 
thin-layer chromatography. It is synthesized on mitochondrial ribosomes and has nearly the same amino acid composition as the yeast polypeptide ( $R$. Michel, et al., unpublished results). It seems possible that this polypeptide is only weakly bound to the ATPase complex in Neurospora crassa and is therefore not isolated with the immunoprecipitate. The same may apply to the polypeptide with a molecular weight of 29000 , which is present in the yeast enzyme and absent in the ATPase complex from Neurospora. The two mitochondrial translation products identified in the Neurospora ATPase may be analogous to the polypeptides with molecular weights of 22000 and 12000 present in oligomycin-sensitive ATPase from yeast.

It seems unlikely that a different set of mitochondrially synthesized polypeptides is necessary for the function of ATPase in yeast and Neurospora crassa. It has yet to be clarified whether or not the lack of two polypeptides in Neurospora ATPase is accompanied by a loss of functional properties of the enzyme.

The authors thank Theodor Bücher for his interest in this work. They are gratelul to Inge $K$ untze for skilful technical assistance and 16) Diana Pfetscher for help in preparing the manuscript. One of the authors (W.S.) had the privilege to work for three weeks in the laboratory of Alexander Tzagoloff. He is grcatly indebted to him for hospitality and many helpful discussions. This work was supported by the Deutsche Forschungsgemeinschaft, Sonderforschungsbercich 51, Medizinische Molekularbiologie und Biochemie.

\section{REFERENCES}

1. Weiss. H., Sebald, W. \& Bücher, Th. (1971) Eur.J. Biochem. 22, $19-26$.

2. Sebald. W.. Weiss. II. \& Jackl, G. (1972) Eur. J. Biochem. 30 , $413-41 ?$
3. Sebald, W., Machleidt, W. \& Otto, J. (1973) Eur. J. Biochen, $38,311-324$.

4. Weiss. H. \& Ziganke, B. (1974) Eur. J. Biochem. 41.63-71.

5. Tzagoluff, A. (1971) J. Bisl. Chem. 246, 3050-- 3056.

6. Schatz, G. (1968) J. Biol. Chem. 243, 2192-2199.

7. Tzagolor, A. (1969) J. Biol. Chem. 244, $5027-5033$.

8. Tzagolofi, A. (1970) J. Biol. Chem. 245. 1545-1551.

9. Tzagolof, A. \& Meagher, P. (1972) J. Biol. Chem. 247, 594-603.

10. Tzagoloff, A. \& Meagher, P. (1971) J. Biol. Chem. 246, $7328-$ 7336.

11. Senior, A. F. \& Brooks, J. C. (1970) Arch. Biochem. Biophyx. 140, 257-266.

12. Schatz, G., Pencfsky, H. S. \& Racker, E. (1967) J. Biol. Chem. $242,2552-2560$

13. Tzagoloff, A. (1969) J. Biol. Chem. 244, 5020-5026.

14. Werner, S. (1974) Eur. J. Biochem. 43, 39-48.

15. Lowry, O. H., Rosebrough, N. J., Farr. A. L. \& Randall, R. J. (1951) J. Biol. Chem. 193, 265-275.

16. Senior, A. E. \& Brooks. J. C. (1971) FEBS Le'll. 17, 327-329.

17. Knowles, A. F. \& Penefsky, H. S. (1972) J. Biol. Chem. 247. 6624-6630.

18. Lambeth, D. O. \& Lardy, H. A. (1971) Eur. J. Biochem. 22, $355-363$.

19. Caterall, W. A., Coty, W. A. \& Pedersen. P. L. (1973) J. Biol. Chem. 248, 7427-7431.

20. Goffeau, A., Landry, Y.. Foury, F. \& Briquet, M. (1973) J. Biol. Chem. 248, 7097-7105.

21. Swanljung, P.. Frigeri, L., Ohlson, K. \& Ernster. L. (1973) Binchim. Biophy:s. Acta, 305, 519-533.

22. Capaldi, R. A. (1973) Biochem. Biophys. Res. Commun. 53, $1331-1337$

23. Mason, T. L., Poyton, R. O., Wharton, D. C. \& Schat7, G. (1973) J. Biol. Chem. 248, 1346--1354.

24. Rubin, M. S. \& T7agoloff, A. (1973).J. Biol. Chem. 248, 42694274.

25. Tzagolof, A., Rubin. M. S. \& Sierra, M. F. (1973) Biochim. Biophys. Acta, 301, 71-104.

26. Tzagolof, A., Akai, A. \& Rubin. M. S. (1974) in Internutional Conference on the Biogenesis of Mirochondria (K'roon. A. M. \& Saccone, C., eds) pp. 405-421, Editrice Adriatica, Bari.

27. Tzagoloff, A. \& Akai, A. (1972) J. Biol. C'hem. 247.65176523.

28. Sierra, M. F. \& Tzagoloff, A. (1973) Proc. Natl Acad. Sci. U.S.A. 70, 3155-3159.

G. Jackl and W. Sebald, Institut für Physiologische Chemie und Physikalische Biochemie der Ludwig-Maximilians-Universität München, D-8000 München 2, Goethestraße 33, Federal Republic of Germany 